\title{
Parâmetros clínicos, hematológicos e bioquímicos de novilhas com hipocalcemia subclínica pré-parto suplementadas com dieta aniônica
}

\author{
[Anionic diet on clinical, haematological and biochemical parameters of heifers with \\ subclinical hypocalcemia prepartum] \\ C. Pizoni ${ }^{1}$, J.O. Feijó ${ }^{1}$, U.S. Londero ${ }^{1}$, R.A. Pereira ${ }^{1}$, M.N. Corrêa ${ }^{1}$, C.C. Brauner ${ }^{1}$, \\ E.G. Xavier ${ }^{2}$, F.A.B.D. Pino ${ }^{1}$, V.R. Rabassa ${ }^{1 *}$ \\ ${ }^{1}$ Núcleo de Pesquisa, Ensino e Extensão em Pecuária - NUPEEC - Universidade Federal \\ de Pelotas - UFPEL - Pelotas, RS \\ ${ }^{2}$ Médico veterinário - Rio Grande, RS
}

\begin{abstract}
RESUMO
A hipótese do presente estudo consiste em que uma dieta aniônica prolongada acarretaria uma mobilização mais rápida do cálcio sanguíneo. O objetivo proposto foi avaliar parâmetros clínicos, hematológicos e bioquímicos de novilhas, com hipocalcemia subclínica, submetidas a diferentes períodos de fornecimento de dieta aniônica no pré-parto. Foram utilizadas nove novilhas da raça Holandês induzidas à hipocalcemia subclínica no pré-parto, divididas em três grupos: $\mathrm{G} 0$ = sem dieta aniônica antes da indução; G11 = 11 dias de dieta aniônica pré-indução; e G15 = 15 dias de dieta aniônica pré-indução. Foi realizado exame clínico antes e depois da indução, e avaliaram-se cálcio total e ionizado, magnésio e albumina nos dias -2, 0, 1, 2 e 3 (dia 0 = momento da indução) e parâmetros hematológicos nos dias 0,1 , 2 e 3. O G11 apresentou maiores concentrações de cálcio total e ionizado que o G0 e maiores níveis de cálcio total que o G15 ( $\mathrm{P}<0,01)$. O magnésio teve maiores valores no G15 quando comparado aos outros grupos $(\mathrm{P}<0,01)$. O G0 apresentou os maiores valores de monócitos e neutrófilos bastonetes $(\mathrm{P}<0,01)$. A dieta aniônica por 11 dias é suficiente para manter a homeostase do cálcio e a resposta leucocitária em novilhas desafiadas a uma diminuição do cálcio sanguíneo.
\end{abstract}

Palavras-chave: dieta pré-parto, cálcio, nulíparas, células de defesa

\begin{abstract}
This study's hypothesis is that cows receiving anionic diet for a longer period respond more quickly to decreased blood calcium. The aim was to evaluate the heifers' clinical, hematological, and biochemical parameters, with subclinical hypocalcemia, subjected to different periods of anionic diet supply during antepartum. Nine heifers were induced to subclinical hypocalcemia during antepartum, sorted in 3 groups: $G 0=$ no anionic diet before induction; G11= eleven days of anionic diet before induction; and G15 = fifteen days of anionic diet before induction. Examinations were held before and after induction and total and ionized calcium, magnesium and albumin were evaluated from days -2, 0, 1, 2 and 3, day 0 being the moment of induction; hematologic parameters were evaluated at days 0, 1, 2 and 3. G11 presented a higher total and ionized calcium concentration than $G 0$ and higher total calcium concentration than $G 15$ ( $P<0.01)$. Magnesium had its highest values at G15 when compared to the other two groups $(P<0.01)$. G0 presented its highest values of monocytes and neutrophils rods $(P<$ 0.01). The eleven days of anionic diet supply were enough to maintain calcium homeostasis and leukocyte response in heifers challenged to reduction in blood calcium.
\end{abstract}

Keywords: dietary prepartum, calcium, nulliparas, defence cells

Recebido em 22 de julho de 2016

Aceito em 15 de setembro de 2016

*Autor para correspondência (corresponding author)

E-mail: nupeec@gmail.com 


\section{INTRODUÇÃO}

A hipocalcemia é uma doença metabólica que afeta vacas de alta produção de leite no período pré-parto e início de lactação, quando há um rápido declínio nas concentrações de cálcio total e ionizado no sangue, devido à mobilização desse mineral para a formação fetal e a produção de leite (Lean et al., 2006). O sistema de homeostase do cálcio, controlado por três hormônios: o paratormônio (PTH), o calcitriol $\left(1,25(\mathrm{OH})_{2} \mathrm{D}_{3}\right)$ e a calcitonina, demora em torno de 72 horas para se tornar ativo, por isso o aumento súbito da demanda do mineral no início da lactação faz com que esse sistema não consiga suprir suas necessidades de cálcio (Goff, 2008), que são de sete a 10 vezes maiores nesse período (Horst et al., 2005). Os níveis fisiológicos de cálcio total em uma vaca adulta devem permanecer entre 8,5 e $10 \mathrm{mg} / \mathrm{dL}$. Vacas com níveis entre 8,0 e 5,5mg/dL são consideradas em hipocalcemia subclínica, enquanto aquelas abaixo de 5,5mg/dL apresentam o quadro clínico da doença (Goff, 2014).

A hipocalcemia subclínica está associada a diversos distúrbios metabólicos do pós-parto. A diminuição do cálcio total e do cálcio ionizado interfere em vários processos que envolvem tanto a contração celular, refletindo na motilidade gastrointestinal e diminuindo a ingestão de matéria seca (IMS), o que ocasiona problemas metabólicos, como síndrome da vaca caída (Brozos et al., 2011), cetose (Kara, 2013) e deslocamento de abomaso (Chapinal et al., 2011), quanto a contração uterina, causando retenção de placenta (Martinez et al., 2012). Além disso, a queda do cálcio pode reduzir a capacidade das células do sistema imune de responder a estímulos, contribuindo para infecções como a mastite e a metrite (Kimura et al., 2006; Martinez et al., 2012), devido a sua função na sinalização celular.

Como estratégia preventiva, os sais aniônicos têm sido utilizados a fim de auxiliar na homeostase do cálcio e na redução dos distúrbios metabólicos no pós-parto. A adição de ânions, como cloro e enxofre à dieta pré-parto, induz na vaca uma acidose metabólica que auxilia a reabsorção óssea e a absorção intestinal de cálcio (Goff, 2014), visto que o organismo tenta compensar a acidificação do $\mathrm{pH}$ sanguíneo aumentando os níveis de cálcio no sangue (Gaynor et al., 1989). Assim, dietas ricas em ânions aumentam a reabsorção osteoclástica e a síntese de $1,25(\mathrm{OH})_{2} \mathrm{D}_{3}$ em vacas (Goff et al., 2014), os quais são controlados pelo PTH.

A resposta do organismo animal à adição de sais aniônicos à dieta é rapidamente perceptível. Em 48 horas após o início do fornecimento da dieta, o pH sanguíneo já está levemente acidificado. Porém, acredita-se que seja necessário de cinco a sete dias para que o efeito da redução do $\mathrm{pH}$ sanguíneo se manifeste nos mecanismos de homeostase do cálcio (Santos et al., 2011), contudo, nos sistemas produtivos, o uso dessa dieta é geralmente indicado durante, no mínimo, 21 dias.

Assim, a hipótese deste estudo é que vacas que recebem dieta aniônica por um período maior respondem mais rapidamente à diminuição do cálcio sanguíneo, demonstrando menos alterações em parâmetros bioquímicos, clínicos e hematológicos.

O objetivo do estudo foi avaliar os parâmetros clínicos, hematológicos e bioquímicos de novilhas leiteiras induzidas à hipocalcemia subclínica submetidas a diferentes períodos de fornecimento de dieta aniônica.

\section{MATERIAL E MÉTODOS}

O experimento foi realizado em uma propriedade leiteira ao sul do Rio Grande do Sul, no município de Rio Grande, nas coordenadas geográficas $32^{\circ} 16$ 'S, $52^{\circ} 32^{\prime} \mathrm{E}$.

Foram utilizadas nove novilhas da raça Holandês, entre 21 e 15 dias pré-parto, em sistema de criação semiextensivo, com escore de condição corporal uniforme $(\mathrm{ECC}=3)$ (Edmonson et al., 1989), distribuídas aleatoriamente entre os grupos. Foi realizada análise bromatológica e mineral da pastagem e do concentrado fornecido para os diferentes grupos (Tab. 1). 
Tabela 1. Ingredientes e composição nutricional da dieta pré-parto

\begin{tabular}{|c|c|c|}
\hline Ingredientes & $\begin{array}{c}\text { Dieta total } \\
\text { G0 }\end{array}$ & $\begin{array}{l}\text { Dieta total } \\
\text { G11 e G15 }\end{array}$ \\
\hline Pastagem de azevém & 583 & 25 \\
\hline Concentrado 1 & $\begin{array}{c}30,5 \\
-\end{array}$ & 416 \\
\hline Feno de hemártria & 41,6 & 33,3 \\
\hline Composição nutricional & $\%$ & $\%$ \\
\hline MS & 95,29 & 94,77 \\
\hline Proteína bruta (PB) & 12,55 & 15,96 \\
\hline Proteína solúvel \%PB & 29,10 & 29,10 \\
\hline PIDN $\% \mathrm{~PB}^{2}$ & 26,00 & 26,00 \\
\hline PIDA $\% \mathrm{~PB}^{3}$ & 13,55 & 13,55 \\
\hline $\mathrm{FDN}^{4}$ & 60,58 & 45,92 \\
\hline FDA $^{5}$ & 41,46 & 30,87 \\
\hline Lignina & 6,04 & 6,04 \\
\hline Lignina $\%$ FDN & 9,30 & 9,30 \\
\hline Açúcares & 6,88 & 6,88 \\
\hline Lipídeos & 1,69 & 3,64 \\
\hline Cinzas & 9,33 & 10,27 \\
\hline Cálcio & 0,35 & 0,81 \\
\hline Fósforo & 0,24 & 0,58 \\
\hline Potássio & 1,45 & 1,40 \\
\hline Magnésio & 0,26 & 0,41 \\
\hline Enxofre & 0,23 & 0,45 \\
\hline $\operatorname{DCAD}^{6}(/ 100 \mathrm{~g} \mathrm{MS})$ & $+51,2$ & $-41,40$ \\
\hline
\end{tabular}

${ }^{1}$ Concentrado composto por 33,7\% de milho moído, $28 \%$ de farelo de soja, $30 \%$ de farelo de arroz, 3,3\% de calcário, $4 \%$ de sal aniônico e $1 \%$ de premix vitamínico; ${ }^{2} \mathrm{PIDN} \% \mathrm{~PB}$ - proteína insolúvel em detergente neutro relativa a \% de proteína bruta; ${ }^{3} \mathrm{PIDEA} \% \mathrm{~PB}$ - proteína insolúvel em detergente ácido relativa a \% de proteína bruta; ${ }^{4} \mathrm{FDN}$ - fibra em detergente neutro; ${ }^{5}$ FDA - fibra em detergente ácido; ${ }^{6}$ DCAD - dieta cátion-aniônica.

Os animais foram divididos em três grupos de acordo com o fornecimento da dieta aniônica e todos os grupos foram induzidos à hipocalcemia subclínica. O grupo G0 (n=3) não havia recebido a dieta aniônica até o momento da indução de hipocalcemia subclínica. No grupo G11 $(n=3)$, a indução de hipocalcemia subclínica foi realizada após fornecimento de dieta aniônica por um período de 11 dias. No grupo G15 (n=3), as novilhas foram induzidas à hipocalcemia subclínica após fornecimento de 15 dias de dieta aniônica.

Para realização da indução de hipocalcemia subclínica, todas as novilhas foram cateterizadas na veia marginal da orelha. Foi realizada tricotomia da orelha e assepsia local com solução de PVPI 2\%. Posteriormente, o vaso foi puncionado utilizando-se um cateter intravenoso $20 \mathrm{G} \times 12$ (BD I-Cath $^{\mathrm{tm}}$, BD, 1Becton Drive, Franklin Lakes, NJ/ EUA). Os três grupos foram submetidos ao protocolo de indução de hipocalcemia subclínica pela infusão endovenosa de uma substância quelante de cálcio (Jorgensen et al., 1999). A administração da solução foi mantida por um período de seis horas.

As coletas de sangue foram realizadas por punção da veia coccígea, utilizando-se o sistema Vacutainer (BD Diagnostics, São Paulo, Brasil), sendo coletadas amostras de sangue em dois tubos: um tubo contendo EDTA $10 \%(5 \mathrm{~mL})$ para realização de leucograma e fibrinogênio e outro sem anticoagulante $(10 \mathrm{~mL})$ tanto para análise bioquímica, sendo determinados os parâmetros de cálcio total $(\mathrm{CaT})$, magnésio $(\mathrm{Mg})$, albumina e proteínas séricas totais, quanto para análise hemogasométrica para avaliação de $\mathrm{pH}$ sanguíneo, pressão de gás carbônico $\left(\mathrm{pCO}_{2}\right)$, pressão de oxigênio $\left(\mathrm{pO}_{2}\right)$, bicarbonato $\left(\mathrm{HCO}^{3}\right)$, tensão de gás carbônico $\left(\mathrm{TCO}_{2}\right)$, saturação de oxigênio $\left(\mathrm{SO}_{2} \%\right)$, sódio $(\mathrm{Na})$ e potássio $(\mathrm{K})$.

As coletas de sangue foram iniciadas dois dias antes do protocolo de indução de hipocalcemia para avaliação do valor basal do cálcio 
sanguíneo. No dia da indução, foram coletadas amostras de sangue imediatamente antes do seu início (0h) até 12 horas após o início, e a média entre os momentos 0,6 e 12 caracterizou o dia 0. Posteriormente, as coletas foram realizadas nos dias 1, 2 e 3 a partir da indução. Após a coleta, o sangue foi submetido à centrifugação a $1800 x \mathrm{~g}$ para obtenção de amostras de plasma e soro, as quais foram identificadas e congeladas a $-70^{\circ} \mathrm{C}$.

Os níveis séricos de $\mathrm{CaT}, \mathrm{Mg}$, albumina e proteínas séricas totais foram analisados por colorimetria, utilizando-se kits enzimáticos (Labtest Diagnóstica S.A., Brasil). Para a leitura, foi usado o espectrofotômetro de luz visível (FEMTO 700Plus, FEMTO Indústria e Comércio de Instrumentos, São Paulo, Brasil). As proteínas séricas totais foram quantificadas para obtenção do valor estimado de cálcio ionizado (iCa) por meio da fórmula $(\mathrm{iCa}=6 \mathrm{x} \mathrm{Ca}-[(0,19 x$ proteínas séricas totais $)+\mathrm{Alb} / 3] /(0,19 \mathrm{x}$ proteínas séricas totais)+ Alb+ 6) (Labtest Diagnóstica S.A., Brasil, Ref 90). Também foi realizada análise de hemogasometria por meio do equipamento iSTAT $^{\circledR} 1$ (Abbott, EUA), em que foram avaliados pH sanguíneo, pressão de gás carbônico $\left(\mathrm{pCO}_{2}\right)$, pressão de oxigênio $\left(\mathrm{pO}_{2}\right)$, bicarbonato $\left(\mathrm{HCO}^{3}\right)$, tensão de gás carbônico $\left(\mathrm{TCO}_{2}\right)$, saturação de oxigênio $\left(\mathrm{SO}_{2} \%\right)$, sódio $(\mathrm{Na})$ e potássio $(\mathrm{K})$.

A avaliação de leucócitos totais foi realizada por reação de impedância, utilizando-se o contador de células semiautomático Celm CC-530 (Celm, Brasil); o diferencial de leucócitos foi realizado por meio de esfregaços sanguíneos corados com panótipo (Laborclin, Brasil), e a leitura foi feita no microscópio Nikon Eclipse E200 (Nikon, Japão) com um aumento de 1000x. Para a análise de fibrinogênio, amostras de sangue foram colocadas em microcapilares com uma das extremidades fechadas; logo após, foram centrifugadas por cinco minutos a uma rotação de 18.000xg na centrífuga de micro-hematócrito digital LB-116/30 (Benfer, Brasil) e colocadas em banho-maria a $56^{\circ} \mathrm{C}$, por cinco minutos, para depois serem quantificadas utilizando-se refratômetro manual para determinação de proteína e densidade específica em soro ou urina (Biobrix, Brasil).

Foi realizado exame clínico nos animais antes de se iniciar o protocolo de indução à hipocalcemia subclínica e logo após o fím da indução $(0$ e 6 horas). Consideraram-se frequência cardíaca
(FC), respiratória (FR), temperatura $\left(\mathrm{T}^{\mathrm{o}}\right)$, movimentos ruminais (MR), tempo de preenchimento capilar (TPC), desidratação e coloração de mucosas (Dirksen et al., 1993).

Para realização da análise estatística dos dados obtidos, utilizou-se o programa Statistical Analysis System (2009). Foi utilizada análise de variância com Mixed Model para comparação dos grupos, coletas e sua interação (grupo $x$ coleta), por meio do teste de Tukey HSD $(\mathrm{P}<0,05)$.

Este estudo foi aprovado pelo Comitê de Ética e Experimentação Animal da Universidade Federal de Pelotas (Cod.0388).

\section{RESULTADOS E DISCUSSÃO}

Dos parâmetros bioquímicos avaliados (Tab. 2), houve diferença nos valores de cálcio total entre os grupos durante todo o período $(\mathrm{P}<0,01)$, sendo seus níveis maiores no G11 em comparação aos grupos G0 e G15 (Fig. 1A). O cálcio ionizado também foi diferente entre os grupos $(\mathrm{P}<0,01)$, tendo o G11 apresentado níveis maiores que o G0 e iguais ao G15 (P>0,05). Na interação grupos $x$ dias, os níveis de cálcio ionizado foram maiores no $\mathrm{G} 11(\mathrm{P}=0,01)$ em relação aos grupos G0 e G15 nos dias 0, 1 e 3 (Fig. 1B). Assim, o fornecimento de dieta aniônica por 11 dias apresentou os melhores resultados para os níveis de cálcio.

A dieta aniônica fornecida de três a quatro semanas antes do parto pode trazer benefícios ao metabolismo do cálcio e à saúde da vaca antes e depois do parto, assim como nos desempenhos produtivo e reprodutivo (Moore et al., 2000). Porém, no presente estudo, foi possível observar que, com apenas 11 dias de fornecimento de dieta, as vacas conseguiram adaptar o organismo à queda de cálcio (Fig. 1A), recuperando-se da hipocalcemia subclínica, indicando que a dieta pode ser fornecida por um período menor já com os efeitos desejáveis sobre a homeostase do cálcio. Em contribuição a esses achados, Weich et al. (2013) determinaram o comportamento pós-parto de vacas que receberam dieta aniônica 42 e 21 dias antes do parto. Em seu estudo, entretanto, os dois períodos de suplementação se comportaram da mesma forma no pós-parto e não foram eficientes em prevenir a hipocalcemia subclínica. Assim, os maiores níveis de cálcio no 
G11, quando comparado ao G15, demonstram que um período de apenas 11 dias é suficiente para serem obtidos os efeitos da dieta aniônica sobre o metabolismo do cálcio, enquanto com 15 dias de dieta esse efeito já não é observado. Ainda, os valores de cálcio total e ionizado no
G11 foram maiores em todo o período comparado aos animais que não recebiam a dieta (Fig. 1A e 1B). Esse resultado já era previsto, uma vez que o objetivo da dieta aniônica é auxiliar na mobilização do cálcio para prevenção da hipocalcemia.

Tabela 2. Parâmetros bioquímicos e hematológicos (média \pm erro-padrão da média) avaliados em novilhas pré-parto induzidas à hipocalcemia subclínica recebendo dieta aniônica por diferentes períodos

\begin{tabular}{|c|c|c|c|c|c|c|c|c|c|c|c|c|}
\hline \multirow{3}{*}{$\begin{array}{l}\text { Parâmetros } \\
\text { Bioquímicos }\end{array}$} & \multirow{2}{*}{\multicolumn{3}{|c|}{ G0 }} & \multirow{2}{*}{\multicolumn{3}{|c|}{ G11 }} & \multirow{2}{*}{\multicolumn{3}{|c|}{ G15 }} & \multicolumn{3}{|c|}{ Valor de P } \\
\hline & & & & & & & & & & Grupo & Dia & Grupo $x$ dia \\
\hline & \multirow{2}{*}{\multicolumn{3}{|c|}{$2,54 \quad(0,13)$}} & \multirow{2}{*}{\multicolumn{3}{|c|}{$2,68 \quad(0,14)$}} & & & & & & \\
\hline Albumina (mg/dL) & & & & & & & \multicolumn{3}{|c|}{$2,98 \quad(0,13)$} & 0,13 & 0,31 & 0,43 \\
\hline Cálcio total $(\mathrm{mg} / \mathrm{dL})$ & \multicolumn{3}{|c|}{$8,69^{* * \mathrm{~b}}(0,19)$} & \multicolumn{3}{|c|}{$9,97^{* * \mathrm{a}} \quad(0,20)$} & \multicolumn{3}{|c|}{$9,28^{* * \mathrm{~b}} \quad(0,18)$} & $<0,01$ & $<0,01$ & 0,36 \\
\hline Cálcio ionizado (mg/dL) & \multicolumn{3}{|c|}{$4,94^{* * \mathrm{~b}}(0,14)$} & \multicolumn{3}{|c|}{$5,99^{* * \mathrm{a} a}(0,15)$} & \multicolumn{3}{|c|}{$5,11^{* * a b} \quad(0,14)$} & $<0,01$ & $<0,01$ & 0,01 \\
\hline Magnésio $(\mathrm{mg} / \mathrm{dL})$ & \multirow{2}{*}{\multicolumn{3}{|c|}{$1,73^{* *_{\mathrm{c}}} \quad(0,05)$}} & &, $93^{* * \mathrm{~b}}(0,06$ & & \multicolumn{3}{|c|}{$2,41^{* * a}(0,05)$} & $<0,01$ & $<0,01$ & 0,03 \\
\hline Fibrinogênio (mg/dL) & \multicolumn{2}{|r|}{$650(69,9)$} & & & $450(84,5$ & & \multicolumn{3}{|c|}{$555(69,9)$} & 0,22 & 0,88 & 0,49 \\
\hline Hematológicos & $\begin{array}{c}\text { Absoluto } \\
(/ \mu \mathrm{L})\end{array}$ & \multicolumn{2}{|l|}{$\begin{array}{c}\text { Relativo } \\
(\%)\end{array}$} & $\begin{array}{c}\text { Absoluto } \\
(/ \mu \mathrm{L})\end{array}$ & \multicolumn{2}{|l|}{$\begin{array}{l}\text { Relativo } \\
(\%)\end{array}$} & $\begin{array}{c}\text { Absoluto } \\
(/ \mu \mathrm{L})\end{array}$ & \multicolumn{2}{|l|}{$\begin{array}{c}\text { Relativo } \\
(\%)\end{array}$} & & & \\
\hline Leucócitos totais & 12.670 & 100 & $(1,77)$ & 12.600 & 100 & $(1,83)$ & 10.600 & 100 & $(1,77)$ & 0,23 & 0,11 & 0,83 \\
\hline Neutrófilos bastonetes & 405,44 & $3,20^{* * \mathrm{a}}$ & $(0,30)$ & 214,2 & $1,70^{* * \mathrm{~b}}$ & $(0,35)$ & 208,82 & $1,97^{* * \mathrm{~b}}$ & $(0,29)$ & $<0,01$ & 0,57 & 0,16 \\
\hline Eosinófilos & $1.107,35$ & 8,74 & $(1,92)$ & $1.179,36$ & 9,36 & $(2,02)$ & 856,48 & 8,08 & $(1,89)$ & 0,89 & 0,64 & 0,06 \\
\hline Linfócitos & 618,29 & 4,88 & $(4,27)$ & 626,22 & 4,97 & $(4,46)$ & 526,82 & 4,97 & $(4,20)$ & 0,98 & 0,02 & 0,11 \\
\hline Monócitos & 490,32 & $3,87^{* * a}$ & $(0,43)$ & 316,26 & $2,51^{* * \mathrm{~b}}$ & $(0,49)$ & 172,78 & $1,63^{* * \mathrm{~b}}$ & $(0,40)$ & $<0,01$ & 0,61 & 0,61 \\
\hline Neutrófilos segmentados & $4.573,87$ & 36,1 & $(3,64)$ & $4.586,4$ & 36,4 & $(3,83)$ & $4.081,0$ & 38,5 & $(3,58)$ & 0,87 & $<0,01$ & $<0,01$ \\
\hline
\end{tabular}

${ }^{1} \mathrm{G} 0$ - animais que passaram por indução à hipocalcemia subclínica sem adição de dieta aniônica; ${ }^{2} \mathrm{G} 11$ - animais que passaram por indução à hipocalcemia subclínica após já estarem recebendo a dieta aniônica há 11 dias; ${ }^{3} \mathrm{G} 15$ animais que passaram por indução à hipocalcemia subclínica após receberem a dieta aniônica há 15 dias. ${ }^{\text {abc }}$ Letras minúsculas diferem entre si na mesma linha. ${ }^{* *}$ Significativo a 1\% de probabilidade. Goff et al., 2014; Jein, 1993; Kaneko et al., 1997.
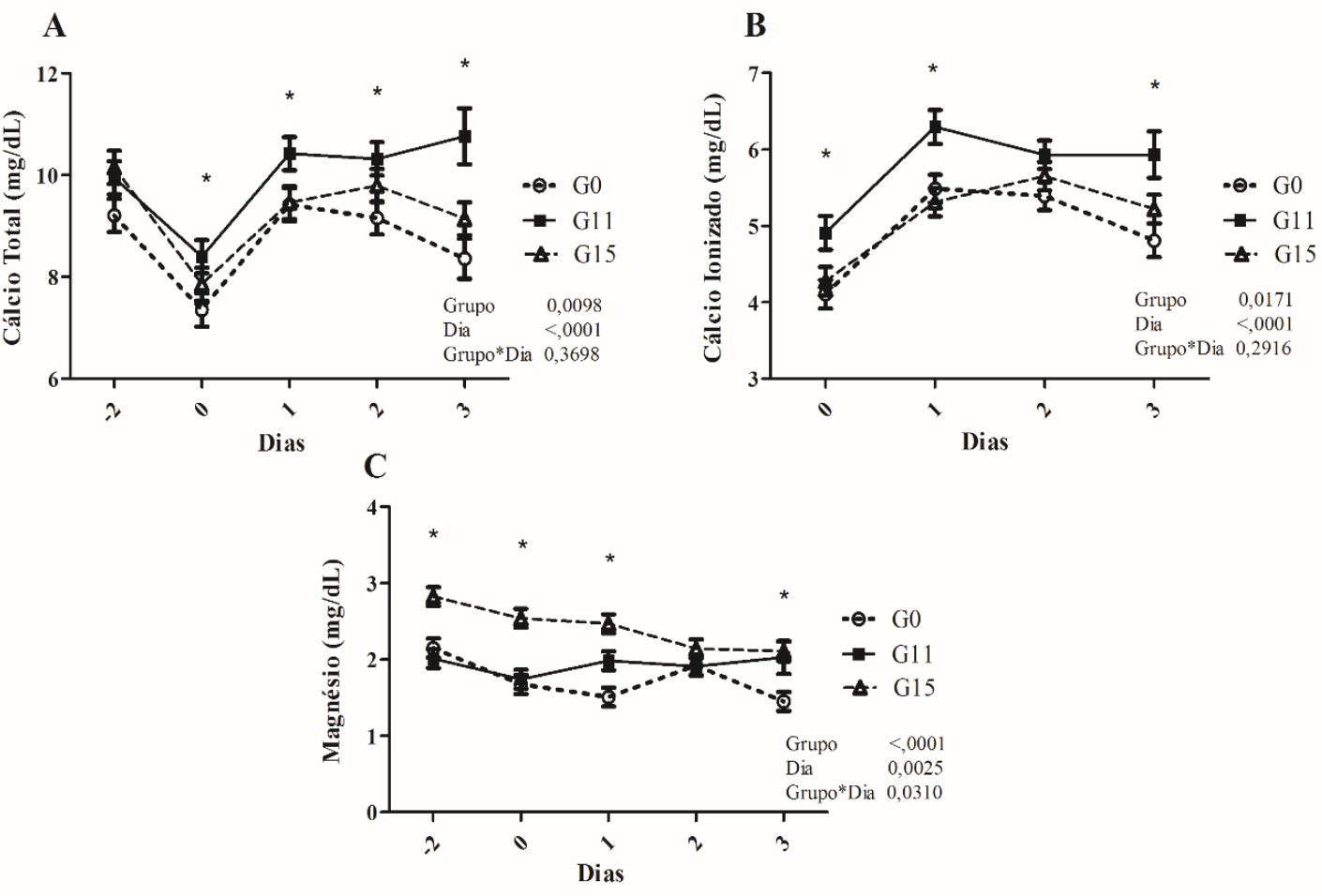

Figura 1. Níveis de cálcio total (A), ionizado (B) e magnésio $(\mathrm{C})(\mathrm{mg} / \mathrm{dL})$ de novilhas leiteiras induzidas à hipocalcemia subclínica, submetidas a diferentes períodos de suplementação de dieta aniônica. *Diferença estatística entre grupos $x$ dia $(\mathrm{P}<0,05)$. 
Na Fig. 1C, observa-se a diferença entre os grupos em relação aos valores de $\mathrm{Mg}$ sanguíneo $(\mathrm{P}<0,01)$. Houve diferença entre os grupos G0 e G15 nos dias -2, 0,1, e 3, sendo G15 maior em todos os períodos; e entre os grupos G0 e G11 nos dias 1 e $3(\mathrm{P}<0,05)$, sendo G11 maior nos dois dias. Os valores de $\mathrm{Mg}$ nos grupos G0 e G15 tiveram uma redução similar durante o período de avaliação, enquanto no G11 se mantiveram constantes. O G15, mesmo apresentando valores de $\mathrm{Mg}$ maiores, teve uma queda de $26 \%$ em seus níveis sanguíneos ao longo do período avaliado, similar ao G0, com queda de $33 \%$, enquanto o G11 manteve-se constante durante todo o período, variando menos de $1 \%$, possivelmente devido ao PTH ativo, que conseguiu manter sua absorção em nível renal durante a queda do cálcio (Goff, 2014). A hipomagnesemia influencia diretamente na sensibilidade dos tecidos ao PTH e na secreção dele diante de uma queda de cálcio, pois o magnésio é um cofator na ativação do AMP cíclico, o mensageiro celular que sinaliza a queda de cálcio no sangue (Goff, 2014). Já a albumina não apresentou diferença entre grupos ou coletas durante o período experimental (Tab. 2).

No leucograma, foi possível observar que o G0 e o G15 tiveram maior porcentagem de neutrófilos segmentados (Fig. 2) somente no segundo dia após hipocalcemia subclínica quando comparados ao G11 $(\mathrm{P}<0,01)$. Houve diferença nos valores de monócitos e neutrófilos bastonetes entre os grupos durante o todo período $(\mathrm{P}<0,01)$, sendo o G0 maior que o G11 e o G15 durante a avaliação. Apesar de os valores de neutrófilos segmentados terem sido menores no G11 quando comparados aos dos outros dois grupos no segundo dia após a queda de cálcio, seria necessária a avaliação da atividade fagocítica deles para confirmar sua capacidade de agir diante de um desafio, como realizado por Martinez et al. (2014), que não observaram diferença na porcentagem de leucócitos, monócitos, linfócitos e neutrófilos nos animais do seu estudo, mas sim diferença na atividade fagocítica dos neutrófilos.

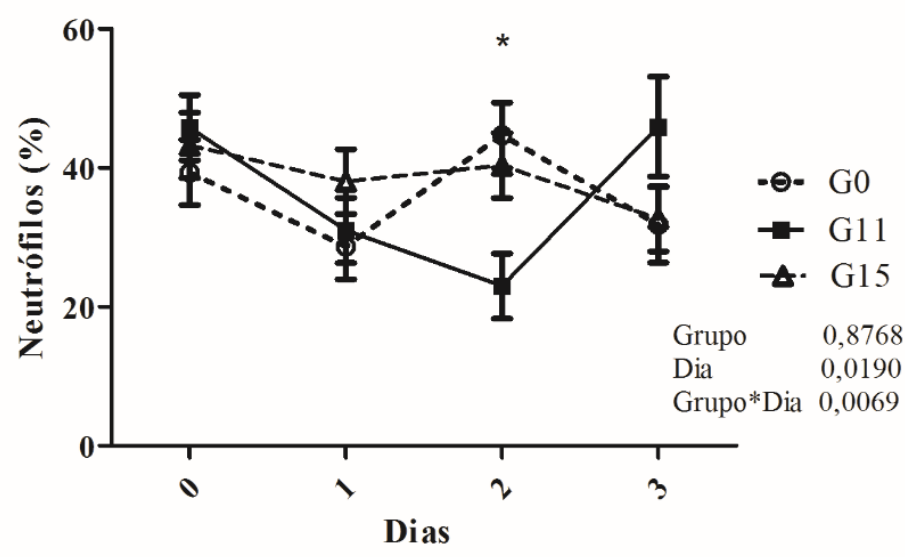

Figura 2. Porcentagem de neutrófilos segmentados de novilhas leiteiras induzidas à hipocalcemia subclínica, submetidas a diferentes períodos de suplementação de dieta aniônica. * Diferença estatística entre grupos $x$ dia $(\mathrm{P}<0,05)$.

Com relação aos monócitos, o G0 apresentou valores maiores principalmente após o cálcio já ter se restabelecido, o que pode ser justificado devido ao fato de o monócito auxiliar na reabsorção óssea por meio do estímulo da secreção de citocinas como interleucina (IL) 1 e 6 e, indiretamente, IL 11 e IL 17, que são responsáveis pelo desenvolvimento e pela reparação óssea (Dong e Wein, 2013). Essa maior quantidade de IL 1 e 6 também é responsável pela maior formação de neutrófilos (Lima, 2013), justificando a maior quantidade de neutrófilos bastonetes (neutrófilos segmentados jovens) no G0. Não houve diferença nos valores de fibrinogênio, leucócitos totais, linfócitos e eosinófilos entre os grupos e entre os períodos (Tab. 2).

O exame clínico realizado nos animais antes e depois da indução à hipocalcemia apresentou 
diferença nos parâmetros de temperatura retal. O G0 apresentou menor temperatura durante o período avaliado, como mostra a Tab. 3. O menor valor da temperatura retal no G0, quando comparado aos outros dois grupos, pode ser explicado neste estudo pelo fato de a queda temporária de cálcio ter reduzido sua função como cofator enzimático, causando alterações na homeostase térmica. Esse resultado não foi encontrado por Martinez et al. (2014). Na avaliação de coloração de mucosa, desidratação e TPC, todos os animais apresentaram os mesmos parâmetros fisiológicos: mucosa rósea, sem presença de desidratação e TPC normal; também não houve diferença na avaliação de movimentos ruminais, frequência cardíaca e respiratória (Dirksen et al., 1993).

Tabela 3. Parâmetros clínicos (média \pm erro-padrão da média) avaliados em novilhas pré-parto induzidas à hipocalcemia subclínica recebendo dieta aniônica por diferentes períodos

\begin{tabular}{|c|c|c|c|c|c|c|c|c|c|}
\hline \multirow{2}{*}{ Parâmetro } & \multirow{2}{*}{\multicolumn{2}{|c|}{ G0 }} & \multirow{2}{*}{\multicolumn{2}{|c|}{ G11 }} & \multirow{2}{*}{\multicolumn{2}{|c|}{ G15 }} & \multicolumn{3}{|c|}{ Valor de P } \\
\hline & & & & & & & Grupo & Dia & Grupo $x$ dia \\
\hline $\begin{array}{l}\text { Frequência cardíaca } \\
\text { (bpm) }\end{array}$ & 81 & $(2,8)$ & 80 & $(2,8)$ & 73 & $(2,8)$ & 0,12 & 0,19 & 0,20 \\
\hline $\begin{array}{l}\text { Frequência respiratória } \\
(\mathrm{mpm})\end{array}$ & 28 & $(4,2)$ & 35 & $(4,2)$ & 32 & $(4,2)$ & 0,51 & 0,62 & 0,34 \\
\hline $\begin{array}{l}\text { Movimentos ruminais } \\
\text { (/2min) }\end{array}$ & 1 & $(0,1)$ & 2 & $(0,1)$ & 1 & $(0,1)$ & 0,29 & 0,50 & 0,09 \\
\hline Temperatura retal $\left({ }^{\circ} \mathrm{C}\right)$ & $38,0^{\mathrm{a}^{*}}$ & $(0,1)$ & $38,6^{\mathrm{b}^{*}}$ & $(0,1)$ & $38,4^{\mathrm{b}^{*}}$ & $(0,1)$ & 0,04 & 0,64 & 0,14 \\
\hline
\end{tabular}

${ }^{1} \mathrm{G} 0$ - animais que passaram por indução à hipocalcemia subclínica sem adição de dieta aniônica; ${ }^{2} \mathrm{G} 11$ - animais que passaram por indução à hipocalcemia subclínica após já estarem recebendo a dieta aniônica há 11 dias; ${ }^{3} \mathrm{G} 15$ animais que passaram por indução à hipocalcemia subclínica após receberem a dieta aniônica há 15 dias. ${ }^{\text {abc Letras }}$ minúsculas diferem entre si na mesma linha. ${ }^{*}$ Significativo a 5\% de probabilidade. Dirksen et al., 1993.

Não houve diferença entre os parâmetros hemogasométricos avaliados $(\mathrm{P}>0,05)$ durante a indução (Tab. 4). Esse resultado pode indicar que, mesmo não havendo acidificação do $\mathrm{pH}$ sanguíneo, pode ter havido acidificação do $\mathrm{pH}$ intracelular, o que pode ter reduzido a concentração de cálcio na célula, como demonstrado por Fernandez et al. (2005), em um estudo que avaliou $\mathrm{pH}$ intracelular de camundongos. Esse resultado é de suma importância, já que a diminuição do cálcio intracelular reduz a funcionalidade da célula (Kimura, et al., 2006). O equilíbrio acidobásico avaliado na hemogasometria não foi alterado durante a queda do cálcio, possivelmente devido a fatores homeostáticos que mantiveram as concentrações de sódio e potássio suprindo as necessidades catiônicas (Goff, 2014).

Tabela 4. Parâmetros hemogasométricos (média \pm erro-padrão da média) avaliados em novilhas pré-parto induzidas à hipocalcemia subclínica recebendo dieta aniônica por diferentes períodos

\begin{tabular}{|c|c|c|c|c|c|c|c|c|c|}
\hline \multirow{3}{*}{$\begin{array}{l}\text { Parâmetro } \\
\mathrm{Ph}(\mathrm{mmHg})\end{array}$} & \multirow{2}{*}{\multicolumn{2}{|c|}{$\mathrm{G}^{(1)}$}} & \multirow{2}{*}{\multicolumn{2}{|c|}{$\mathrm{G} 11^{(2)}$}} & \multirow{2}{*}{\multicolumn{2}{|c|}{$\mathrm{G} 15^{(3)}$}} & \multicolumn{3}{|c|}{ Valor de P } \\
\hline & & & & & & & \multirow{2}{*}{\begin{tabular}{|c|} 
Grupo \\
0,19 \\
\end{tabular}} & \multirow{2}{*}{$\begin{array}{r}\text { Dia } \\
<0,01\end{array}$} & \multirow{2}{*}{$\begin{array}{c}\begin{array}{c}\text { Grupo } \\
x \text { dia }\end{array} \\
0,27\end{array}$} \\
\hline & 7,37 & $(0.01)$ & 7,42 & $(0.01)$ & 7,39 & $(0.01)$ & & & \\
\hline $\mathrm{pCO}_{2}(\mathrm{mmHg})$ & 37,99 & $(1,22)$ & 34,51 & $(1,22)$ & 38,81 & $(1,22)$ & 0,09 & $<0,01$ & 0,31 \\
\hline $\mathrm{pO}_{2}(\mathrm{mmHg})$ & 71,61 & $(14,12)$ & 59,91 & $(14,12)$ & 49,62 & $(14,12)$ & 0,57 & 0,13 & 0,05 \\
\hline $\mathrm{HCO}^{3}(\mathrm{mmol} / \mathrm{L})$ & 22,25 & $(1,45)$ & 23,01 & $(1,45)$ & 24,74 & $(1,45)$ & 0,50 & $<0,01$ & 0,27 \\
\hline $\mathrm{SO}_{2}(\%)$ & 76,55 & $(6,03)$ & 77,00 & $(6,03)$ & 73,61 & $(6,03)$ & 0,91 & 0,10 & 0,37 \\
\hline $\mathrm{Na}(\mathrm{mmol} / \mathrm{L})$ & 139,86 & $(1,47)$ & 143,69 & $(1,47)$ & 140,17 & $(1,47)$ & 0,20 & 0,11 & 0,35 \\
\hline $\mathrm{K}(\mathrm{mmol} / \mathrm{L})$ & 4,01 & $(0,64)$ & 5,31 & $(0,64)$ & 4,09 & $(0,64)$ & 0,28 & 0,36 & 0,42 \\
\hline
\end{tabular}

${ }^{1} \mathrm{G} 0$ - animais que passaram por indução à hipocalcemia subclínica sem adição de dieta aniônica; ${ }^{2} \mathrm{G} 11$ - animais que passaram por indução à hipocalcemia subclínica após já estarem recebendo a dieta aniônica há 11 dias; ${ }^{3} \mathrm{G} 15$ animais que passaram por indução à hipocalcemia subclínica após receberem a dieta aniônica há 15 dias. Kaneko et al., 1997. 
O uso da dieta aniônica geralmente é recomendado durante todo o período pré-parto, que representa ao produtor um custo elevado, mesmo diante dos benefícios que ela gera. Neste estudo, o uso de dieta aniônica por 11 dias se mostrou eficiente na adaptação do organismo ao sistema de homeostase do cálcio, o que sugere que seu uso poderia ser reduzido, mantendo sua eficiência, reduzindo os danos celulares e diminuindo o custo para o produtor.

\section{CONCLUSÃO}

Conclui-se que, diferentemente do esperado, o menor tempo de fornecimento da dieta aniônica não prejudicou a condição hematológica dos animais e foi suficiente para manter a homeostase do cálcio em novilhas desafiadas a uma diminuição do cálcio sanguíneo, além de não ter influenciado na condição clínica deles, portanto um maior período de fornecimento da dieta aniônica não seria necessário para prevenção da hipocalcemia.

\section{REFERÊNCIAS}

BROZOS, C.; MAVROGIANNI, V.S.; FTHENAKIS, G.C. Treatment and control of peri-parturient metabolic diseases: pregnancy toxemis, hypocalcemia, hypomagnesemia. Vet. Clin. N. Am. Food Anim. Pract., v.27, p.105-113, 2011.

CHAPINAL, N.; CARSON, M.E.; DUFFIELD, T.F. et al. The association of serum metabolites with clinical disease during the transition period. J. Dairy Sci., v.94, p.4897-4903, 2011.

DIRKSEN, G.; GRÜNDER, H.D.; STÖBER, M. Rosenberger, exame clínico dos bovinos. 3.ed. Rio de Janeiro: Guanabara, 1993. 420p.

DONG, L.; WEIN, C. Harnessing the power of macrophages/monocytes for enhanced bone tissue engineering. Trends Biotechnol., v.31, p.342-346, 2013.

EDMONSON, A.J.; LEAN, I.J.; WEAVER, L.D. et al. A body condition scoring chart for holstein dairy cows. J. Dairy Sci., v.72, p.68-78, 1989.

FERNANDEZ, R.; GIEBISCH, G.; GEIBEL, J.P. Intracellular $\mathrm{Ca}^{2+}$ modulates $\mathrm{H}^{+}$ATPase activity in intercalated cells from mouse cortical collecting duct (CCD). Faseb J., v.19, p.139, 2005.
GAYNOR, P.J.; MUELLER, F.J.; MILLER, J.K. Parturient hypocalcemia in Jersey cows fed alfalfa haylage-based diets with different cation to anion rations. J. Dairy Sci., v.72, p.2525-2531, 1989.

GOFF, J.P. Calcium and magnesium disorders. Vet. Clin. N. Am. Food Anim. Pract., v.30, p.359381, 2014.

GOFF, J.P. The monitoring, prevention, and treatment of milk fever and subclinical hypocalcemia in dairy cows. Vet. J., v.176, p.5057, 2008 .

GOFF, J.P.; LIESEGANG, A.; HORST, R.L. Diet-induced pseudohypoparathyroidism: a hypocalcemia and milk fever risk factor. J. Dairy Sci., v.97, p.1520-1528, 2014.

HORST, R.L.; GOFF, J.P.; REINHARDT, T.A. Adapting to the transition between gestation and lactation: differences between rat, human and dairy cow. J. Mammary Gland Biol. Neoplasia, v.10, p.141-156, 2005.

JAIN, N.C. Essentials of veterinary hematology. Philadelphia: Lea \& Febiger, 1993. 417p.

JORGENSEN, R.J.; NYENGAARD, N.R.; DANIEL, R.C.W. et al. Induced hypocalcaemia by $\mathrm{Na}_{2}$ EDTA infusion: a review. J. Vet. Med., v.46, p.389-497, 1999.

KANEKO, J.J.; HARVEY, J.W.; BRUSS, M.L. (Eds.). Clinical biochemistry of domestic animals. 5ed. New York: Academic Press, 1997. 932p.

KARA, C. Physiological and metabolic changes during the transition period and the use of calcium propionate for prevention or treatment of hypocalcemia and ketosis in periparturient cows. J. Biol. Environ. Sci., v.7, p.9-17, 2013.

KIMURA, K.; REINHARDT, T.A.; GOFF, J.P. Parturition and hypocalcemia blunts calium signal in immune cells of dairy cattle. J. Dairy Sci., v.89, p.2588-2595, 2006.

LEAN, I.J.; DEGARIS, P.J.; MCNEIL, D.M. et al. Hypocalcemia in dairy cows: meta-analysis and dietary cation anion difference theory revisited. J. Dairy Sci., v.89, p.669-684, 2006. 
LIMA, L.T. Fisiologia do sistema hematopoiético. 2013, 55p. Disponível em: <https://social.stoa.usp.br/articles/0029/1943/Gra nulopoese_110513A.pdf $>$. Acessado em: 20 de set. 2015.

MARTINEZ, N.; RISCO, C.A.; LIMA, F.S. et al. Evaluation of peripartal calcium status, energetic profile, and neutrophil function in dairy cows at low or high risk of developing uterine disease. J. Dairy Sci., v.95, p.7158-7772, 2012.

MARTINEZ N.; SINEDINO, L.D.P.; BISINOTTO R.S. et al. Effect of induced subclinical hypocalcemia on physiological responses and neutrophil function in dairy cows. J. Dairy Sci., v.97, p.874-887, 2014.
MOORE, S.J.; VANDEHAAR, M.J.; SHARMA, B.K. et al. Effects of altering dietary cationanion difference on calcium and energy metabolism in peripartum cows. J. Dairy Sci., v.83, p.2095-2104, 2000.

SANTOS, J.E.P. Distúrbios metabólicos. In: BERCHIELLI, T.T.; PIRES, A.V.; OLIVEIRA, S.G. (Eds.). Nutrição de ruminantes. 2.ed. Jaboticabal: Funep, 2011. p.459-472.

STATISTICAL Analysis System. 9,3. Cari: SAS Institute, 2009.

WEICH, W.; BLOCK, E.; LITHERLAND, N.B. Extended negative dietary cation-anion difference feeding does not negatively affect postpartum performance of multiparous dairy cows. J. Dairy Sci., v.96, p.5780-5792, 2013. 